\title{
Investigating the Social Capital Theory in the University-Private Partnership: A Systematic Review
}

\author{
Maram Hakami \\ University of Technology Sydney; \\ Umm Al-Qura University \\ $\underline{\text { Maram.Hakami@student.uts.edu.au }}$
}

\author{
Sojen Pradhan \\ University of Technology Sydney \\ Sojen.Pradhan@uts.edu.au
}

\author{
Emmanuel Mastio \\ University of Technology Sydney \\ Emmanuel.Mastio@uts.edu.au
}

\begin{abstract}
Literature has recognised 'university-private partnerships' as one of the influential contributors to the economic growth towards building the knowledgebased economy. University-private partnerships is still a progressing phenomenon that has been investigated through the lens of different theories, including the social capital theory that comprises structural, relational, and cognitive dimensions. To date, the influence of social capital theory on transferring knowledge has been investigated; but there has been an inconsistency between studies related to the social capital cognitive dimension compared to other related dimensions. This paper aims to explore how the theoretical lens of social capital theory informs research and learnings about partnerships between universities and private sectors. Overall, 23 studies published within the last two decades are systematically reviewed. Findings from this review lead to a fundamental theoretical framework that addresses the abovementioned inconsistency, a reflection on the current related research themes, and a proposition for future research directions.
\end{abstract}

\section{Introduction and background}

Teaching and research are the main two roles universities have been engaged in our societies. For the last couple of decades, universities have also started contributing to all sectors in different ways of the so-called 'third mission' of universities which act as knowledge producer and transmitter to participate in economic growth by integrating into various crosssector and inter-organisational activities [1]. These activities are mentioned in the related literature as collaboration or relationship between university and industry towards building the 'knowledge-based economy' [1]. University-Private Partnership (UPP) in this paper is referred to as an inter-organisational relationship between the university and the private sector. A growing body of literature has increasingly addressed this phenomenon in the last two decades through different theoretical lenses aiming to address a variety of aspects. Social capital (SC) theory is one of the effective theories that has been investigated to understand inter-organisational relations in several levels of analysis. Literature have recognised the significance of SC in the context of the UPP. The importance of SC factors such as trust, social norms, etc., is reflected in facilitating inter-organisational activities (knowledge transfer (KT) and technology transfer (TT)) between partners towards a successful partnership. Similarly, the lack of SC has been discussed as a KT/TT barrier between partners [2-5]. This present review is conducted to answer the following main research question: "How would the theoretical lens of SC inform research and learnings about UPP?". To answer that, further sub-questions are formulated to guide data analysis and synthesis, as follows. What was the state of the art in the related SCUPP 'literature review studies'? What were the current research themes in the papers that investigate SCUPP? What research methods and research participants' categories were used in the papers to investigate SC-UPP? What were the theoretical contributions aspects of SC-UPP?

Universities as part of academia or higher education institutions (HEIs) are referred to as "organisations that perform a key role within contemporary societies by educating large proportions of the population and generating knowledge" [6]. In addition to providing teaching and conducting research, universities' 'third mission' has been profound, and it is defined as "all activities concerned with the generation, use, application and exploitation of knowledge and other university capabilities outside academic environments" [7]. While The private sector is defined as "a diverse group of financial institutions, intermediaries, multinational companies, micro, small and medium-sized enterprises and cooperatives who operate in the formal and informal sectors engaging in profit-seeking activities with a majority of private ownership - is widely recognised as engine of growth and ingenious source and driver of knowledge generation and innovation" [8]. Historically, UPP has 
received much attention on literature after the 1970s' crisis in the capitalist economic system (petroleum shortages), which caused the academic transformation; where academia and private sectors were forced to collaborate to overcome the crisis by growing and diversifying sources of income [9].

University was also referred to in the literature as academia, and private sector was also referred to in some literature as business, industry, or firms. As well, UPP has been mentioned in literature widely as 'university-industry collaborations', Other terms were also addressed as, 'university-industry cooperation', 'public-private partnerships' in which 'public' in some cases denotes to public research organisations, 'university-industry interactions', 'university-industry partnerships', 'business-university collaborations', 'business-science links' or 'academic engagements'. UPP could also be formed as a 'triple-helix' in which government-university-industry collaborate, or in its extended version, the 'quadruple-helix', where more sectors are involved in order to promote innovation, comprising the government-university-industrypublic (or civil society) relationship. UPP in this paper is defined as the short-term or long-term arrangements between universities and the private sector companies to inter-organisationally access each other's resources through partnership's mechanisms. According to Perkmann and Walsh [10], there are several UPP's mechanisms that were classified into several groups, as illustrated in Table 1.

Table 1. The Mechanisms of UPP [10]

\begin{tabular}{|c|c|}
\hline $\begin{array}{c}\text { Research } \\
\text { partnerships }\end{array}$ & $\begin{array}{l}\text { Inter-organizational arrangements for } \\
\text { pursuing collaborative R\&D. }\end{array}$ \\
\hline Research services & $\begin{array}{l}\text { Activities commissioned by industrial } \\
\text { clients including contract research and } \\
\text { consulting. }\end{array}$ \\
\hline $\begin{array}{l}\text { Academic } \\
\text { entrepreneurship }\end{array}$ & $\begin{array}{l}\text { Development and commercial } \\
\text { exploitation of technologies pursued by } \\
\text { academic inventors through a company } \\
\text { they (partly) own. }\end{array}$ \\
\hline $\begin{array}{l}\text { Human resource } \\
\text { transfer }\end{array}$ & $\begin{array}{l}\text { Multi-context learning mechanisms } \\
\text { such as training of industry employees, } \\
\text { postgraduate training in industry, } \\
\text { graduate trainees and secondments to } \\
\text { industry, adjunct faculty. }\end{array}$ \\
\hline Informal interaction & $\begin{array}{l}\text { Formation of social relationships and } \\
\text { networks at conferences, etc. }\end{array}$ \\
\hline $\begin{array}{l}\text { Commercialization } \\
\text { of property rights }\end{array}$ & $\begin{array}{l}\text { Transfer of university-generated IP } \\
\text { (such as patents) to firms, e.g. via } \\
\text { licensing. }\end{array}$ \\
\hline $\begin{array}{r}\text { Scie } \\
\text { publi }\end{array}$ & $\begin{array}{l}\text { Use of codified scientific knowledge } \\
\text { within industry. }\end{array}$ \\
\hline
\end{tabular}

This paper is organised by first stating a brief literature review on SC theory. Next, the research methodology and data description are reported. Then, it covers results and discussion and finally the conclusion and future directions of this study to conclude.

\section{Social capital (SC) theory}

Historically, the term SC originally was applied in sociology and political science. It appeared early on in the book of Jacobs [11], "The death and life of great American cities", in which she studied diversities of relationships and how that formulated trust and other relational actions among city neighbourhoods. According to Häuberer [12], the two theorists Bourdieu (1983) and Coleman (1988), took credit for shaping SC when they first introduced it systematically. Since then, SC has widely spread in the literature of IS and different other disciplines studies including, intellectual capital [13], economic development [14], innovation performance [15], academic research performance [16], knowledge sharing in the HEIs [17], and KT [2, 18] or TT [19]. SC was defined widely by several well-known authors in their seminal studies, including Coleman [20], Bourdieu and Wacquant [21], Woolcock [14], Putnam [22], Portes [23], Granovetter [24], and Adler and Kwon [25]; based on a variety of areas and applications. Coleman [20] stated that SC is not a single entity; thus, the definition based on its function is "a variety of different entities, with two elements in common: they all consist of some aspect of social structures, and they facilitate certain actions of actors whether persons or corporate actors within the structure"; While Bourdieu and Wacquant [21] defined SC as "the sum of the resources, actual or virtual, that accrues to an individual or a group by virtue of possessing a durable network of more or less institutionalised relationships of mutual acquaintance and recognition". Furthermore, Nahapiet and Ghoshal [13] defined SC as "the sum of the actual and potential resources embedded within, available through, and derived from the network of relationships possessed by an individual or social unit".

SC has been studied on the level of the individual, group, intra- or inter-organisation, and community. SC is an 'umbrella concept' according to Adler and Kwon [25], as there is no such one affirmed definition for SC, resulting in various interpretations by the authors. Therefore, SC is a multidimensional concept [22]. From the points of view in which those were obtained, Woolcock and Narayan [26] examined SC from different aspects, involving communitarian view, networks view, institutional view, and synergy view. As well, scholars in the SC also perceived SC resources as internal (bonding/ linking) or external (bridging) resources, whereas others have involved 
both internal and external resources when they measure SC. In view of that, Nahapiet and Ghoshal [13] emphasised the influence of the SC in creating a new intellectual capital by proposing the three SC internal and external resources named as SC dimensions; comprising structural, relational, and cognitive; in which each one of them involves several factors.

Based on a rich body of literature, SC dimensions that were proposed by Nahapiet and Ghoshal [13] received a wide acceptance to be adopted in many related studies. Every SC dimension focuses on a cluster of aspects, though they are thoroughly interrelated. The structural dimension is associated with the relationships of social networks, while the relational dimension is related to the nature of embedded resources in the relationships. Finally, the cognitive dimension refers to resources that provide shared interpretations between partners [13]. In the following sections, selected factors in each dimension are described.

As Nahapiet and Ghoshal [13] stated, SC mainly is "who you know affects what you know". The structural SC dimension comprises a pattern of interconnection and relationship networks of interorganisational entities, including network ties, tie strength, and networks configurations. Network ties are how organisations' stakeholders relate to each other [18], considered to be a crucial aspect of SC; which is associated with the ties among network entities that lead to foster UPP [25]. Tie strength is defined as a "combination of the amount of time, the emotional intensity, the intimacy (mutual confiding), and the reciprocal services which characterise the tie" [24]. As well, network configurations reveal opportunities to develop a connection and build a network among organisations, in which actors would be more willing to transfer knowledge and resources to those who already got a closed relationship [18, 27].

The relational SC dimension is the most influential component of $\mathrm{SC}$ as it concentrates on social interactions from the perspective of characteristics and quality of those relationships. It involves three factors, trust, norms, and obligations. Trust is a psychological state that developed over time and referred to the willingness of organisations on decreasing their controlling and confidentiality policies over transferring their resources [18]. Norms (or norms of reciprocity) as was described by Coleman [20], "where a norm exists and is effective, it constitutes a powerful though sometimes fragile form of social capital". Social norms are important for openness and collaborations, especially in the 'knowledge-intensive firms' [25], such as universities. Norms refer to the degree of consensus in the social system, while obligations represent "a commitment or duty to undertake some activity in the future" [13].

The cognitive SC dimension refers to "resources providing shared representations, interpretations, and systems of meaning among parties" [13]. It clusters two factors, shared goals and culture. The degree to which partners share understanding towards the success of the project is termed as 'shared goals', while the degree to which partnership be affected by the social norms is termed as 'shared culture' [18]. Furthermore, this dimension would be identified as shared values, vision, meaning, culture, and common understanding $[16,18]$.

\section{Methodology}

To answer the research questions, a systematic literature review is conducted following the principles and process of Tranfield, et al. [28] which are similar to major previous 'systematic reviews studies' in the UPP field [4, 6, 29]. In the first step, multiple iterations of searching through selected databases and publishers were applied. The initial search was done via wellknown databases and peer-reviewed journals that were mentioned in the related studies in the UPP field, EBSCOhost, Scopus, ProQuest, Web of Science, Emerald, ScienceDirect, and Taylor \& Francis. The following search boundaries were applied to filter the initial results: only peer-reviewed studies, the timeframe is over two decades from 2000 to 2021 (present), language is English, and only research papers type of scholarly journals and conference papers; while other document types were omitted.

Search terms were, 'social capital', 'universit* OR academ* OR public*, ' industr* OR business* OR firm* OR privat*', and 'collaborat* OR cooperat* OR engag* OR organi* OR link* OR relat* OR research* OR partner*'. Multiple combinations of Boolean search strings were applied through title, abstract and keywords. Additional terms that involve SC's factors such as trust, etc. were also applied through the abstract to make sure that all cases were covered; however in many cases it revealed studies that did not apply SC theory in particular. As well, it is noted that 'public*' and 'privat*' search terms did produce wide general public and private sectors studies that were not in the UPP field. Taking into consideration the shared articles among databases, around 39\% of the results were extracted from Scopus database, 27\% ProQuest, $22 \%$ Web of Science, $10 \%$ EBSCOhost, and the $2 \%$ of the results were distributed among the rest of the sources. By applying boundaries and search terms, a total of 707 papers was retrieved. After removing the duplication in each database individually, combining all results, and then eliminating duplicates, 363 papers 
remained. Figure 1 summarises the systematic review protocol. Endnote X9.2 was the reference management software that was used.

In the second step, results were evaluated by scanning the title and abstract based on the inclusion and exclusion criteria in line with the research questions, as shown in Figure 1. In some cases, the introduction and conclusion sections were also scanned.

\begin{tabular}{l} 
The selected electronics sources \\
- EBSCOhost - Scopus - ProQuest - Web of Science \\
- Emerald - ScienceDirect - Taylor \& Francis \\
\hline The initial search boundaries \\
- Only peer-reviewed papers. \\
- Time frame: 2000 - 2021. \\
- Language: English. \\
- Source type: scholarly journals and proceedings. \\
- Document type: research papers of (journal articles and \\
conference papers). \\
Search terms \\
Social capital, universit* OR academ* OR public*, \\
industr* OR business* OR firm* OR privat*, collaborat* \\
OR cooperat* OR engag* OR organi* OR link* OR relat* \\
OR research* OR partner* \\
- Focusing only on the UPP context. \\
- Explicitly examining/ mentioning SC. \\
- Exploring the direct link between university and the \\
private sector. \\
- Involving external actors that lead the partnership (e.g. \\
government). \\
- Exploring a third party between actors (e.g. intermediary). \\
- Examining some factors (e.g. trust) without explicitly \\
mentioning SC. \\
- Focusing only on the one side's aspects (e.g. academics' \\
career).
\end{tabular}

Figure 1. Systematic Review Search Protocol

The first inclusion criteria was that direct UPP should be the core focus. So, as the focus was only on university and the private sector stakeholders, papers that involved other external stakeholders were excluded, such as studies that discussed the 'triplehelix' or 'quadruple-helix' models, studies that included a third party or 'boundary spanning' and intermediaries entities, and studies that explored only independent public research centres outside universities; however, studies that discussed research centres besides universities were included. Moreover, exclusion was also applied on the studies that discussed other educational institutions, like public schools, other than universities in terms of the academic partnership, and studies that addressed partnerships between two or more universities without focusing on the private sector. Finally, studies that focused only one stakeholder's issue were also excluded, (e.g. academics' careers or productivities, or firms' innovation performance), without associating that with the UPP context; however, relevant studies that well demonstrated the actual influence on UPP were included. The second inclusion criteria was that SC should be explicitly examined, in which papers that only mentioned SC without examining it, or studied some SC's factor, e.g. trust, commitment, etc., without explicitly indicating to $\mathrm{SC}$ as a theoretical paradigm were excluded. As well, studies that verbalised SC as one construct formed by its three main dimensions without identifying factors were included only if they met the inclusion criteria. Furthermore, entrepreneurialism's characteristics studies outside the UPP context were also excluded. Finally, studies that focused broadly on the science and technology park without relating to the UPP context were excluded; however, only one paper that studied the direct UPP within the science park was included as it met the inclusion criteria. Furthermore, according to Tranfield, et al. [28], the 'quality assessment' criteria of the 'management research' were applied by evaluating the fit between studies' objectives or research questions and studies' applied methodology. After this second step of filtering, 84 papers remained. Subsequently, a full-reading of those 84 papers was conducted, which further narrowed the relevant research papers to 23 . Figure 2 presents the conducted process of selecting the systematic review studies.

Records identified through database searching

- Conducting several iterations within the search boundaries

- Applying different search strings $(\mathbf{n}=\mathbf{7 0 7})$

\section{Records after duplicates removed}

- Removing duplicates in each database's individually

- Combining the whole results

- Removing duplicates in the final collection

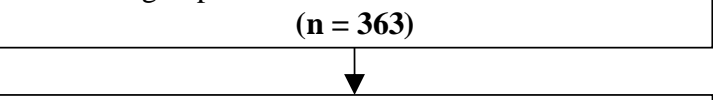

\section{Records screened}

- Applying the Inclusion/ Exclusion criteria

- Reading title and abstract

- In some cases, reading also introduction/ conclusion $(\mathbf{n}=\mathbf{8 4})$

Full-text articles assessed for eligibility

- Applying the Inclusion/ Exclusion criteria

- Reading the full paper

- Applying the 'quality assessment' criteria $(\mathrm{n}=\mathbf{2 3})$

Figure 2. The Selection Process of the Systematic Review Studies 
In the third step, MS Excel 2016 software was used to collate the data extraction and to analyse and synthesise findings based on the research questions to reduce human error and bias. The data extraction sheet was organised as follows: title, authors' name, year of publication, main aim or research questions, research methods, research sample (numbers, participants' category), UPP's mechanisms or activities, country, source's (name, type), document type, database/ publisher's name, SC's level of analysis, SC's dimensions (structural, relational, and cognitive) and SC's factors, other constructs, outcome, and additional theories (if any).

\subsection{Descriptive data}

This systematic review yielded 23 papers that fit the inclusion criteria. Figure 3 demonstrates the distribution of publications per year during the last two decades; the number increased since 2016, reaching the highest publications in 2019. Among papers, only two studies were conference papers, while the rest being journal articles. Furthermore, the top scholarly journal in this systematic review that reported in three articles was 'European Journal of Innovation Management', whereas the following journals were reported in two articles each, 'Journal of Knowledge Management', 'Knowledge Management Research \& Practice', 'Science \& Public Policy', 'The Journal of Technology Transfer', and 'Industry and Innovation'. The rest of the journals were reported in one article each. Moreover, ten of the studies were conducted in the European countries, followed by five studies in the Asian countries, then the rest of other studies were from other continents: two in North America, one in Africa, and one was conducted among three regions, including Europe, Asia, and Australia. In addition, four other 'review studies' which met the objectives of this study were also included.

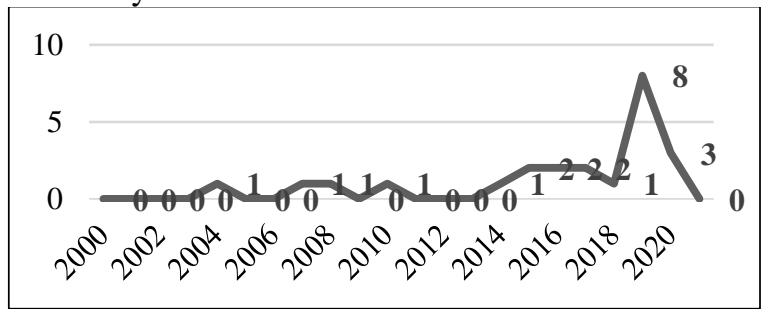

Figure 3. Papers according to the publication year

\section{Results and discussion}

The first research question refers to the state of the art in the related SC-UPP 'review studies' which is shown in Table 2. There were a number of 'review studies' that discussed SC-UPP but were excluded from records for the following reasons. Some of the 'reviews studies' focused on the different aspects of the direct UPP without explicitly mentioning SC [6, $10,29]$, and others that reviewed SC but focused only on the 'triple-helix' model [30]. However, there were a few 'review studies' that were directly focusing on UPP and explicitly examined SC within that context. Table 2 summarises related review studies that met the purpose of this paper. The importance of SC in facilitating resources' transfer towards fostering UPP and organisation's innovation was proved in the following two traditional 'literature reviews' $[2,5]$, one 'systematic review' [4], and one 'comparative review' [3]. According to de Wit-de Vries, et al. [4], it has been proved the positive influence of SC in the context of 'academic engagement', comprising 'collaborative research, contract research and consulting' towards KT success. As well, according to Robertson, et al. [3], by comparing different projects ranging from developed to developing countries, they proved that SC influences differ based on the various environments or regions.

Table 2. A summary of related 'review studies'

\begin{tabular}{|c|c|c|}
\hline Source & $\begin{array}{l}\text { Reviewed } \\
\text { Studies \# }\end{array}$ & Main Aim \\
\hline [2] & N/A & $\begin{array}{l}\text { The purpose of this 'literature review' was } \\
\text { to identify factors that affect KT-UPP and } \\
\text { then to develop a theoretical framework. }\end{array}$ \\
\hline [3] & 9 & $\begin{array}{l}\text { The purpose of this 'comparative review' } \\
\text { was to develop a framework in order to } \\
\text { understand how SC-UPP influence KT } \\
\text { strategies, which then impacts innovation, } \\
\text { by comparing nine studies from three } \\
\text { different stage countries, including } \\
\text { Canada, Malta, and South Africa. }\end{array}$ \\
\hline [4] & 35 & $\begin{array}{l}\text { This 'systematic review' proposed a } \\
\text { theoretical model for the research } \\
\text { partnerships in the context of KT-UPP and } \\
\text { what practices facilitate KT. }\end{array}$ \\
\hline [5] & N/A & $\begin{array}{l}\text { This 'literature review' built a clear } \\
\text { understanding of the UPP impact through } \\
\text { the lens of SC. }\end{array}$ \\
\hline
\end{tabular}

The second research question concerns the current research themes or the nature of the studies. The SC has been applied to a number of UPP studies, which would be perceived as conceptual perspectives that focus theoretically on developing research models and empirical perspectives that mainly studied primary data via a variety of research methods to analyse how SC facilitates UPP, where others even combined data from related primary and secondary sources. In this systematic review, selected papers were classified into two main research streams, knowledge-based and resource-based research themes. The majority of 
papers $(13$, total) $(57 \%)$ was in the knowledge-based theme where they studied the KT/TT through UPP and examined factors that influence from the knowledgebased perspective [2-4, 15, 17, 19, 27, 31-36]. While resource-based themes yielded for 10 papers in total (43\%), where some papers drew insights from the actors' characteristics and how that affected SC-UPP from different perspectives including, academics' research performance or researchers competence [16, 34, 37], partner selection criteria [38], firms' performance and firms' reputations [39], and organisations' experience level [40, 41], Figure 4 described the SC-UPP research themes in the related studies. UPP mechanisms were discussed from the SC point of view and how that would formulate UPP associated with the risk levels (low/ high) [42]. UPP motivations and UPP barriers/challenges were also explored from different points of view through the SC theory lens [40-44]. Regarding UPP mechanisms, as illustrated in Table 1, were also discussed broadly into all papers as network channels between universityprivate sector actors (U-P) or from the perspective of KT/TT channels through UPP, as most papers involved more than one mechanism. Besides, contractbased mechanisms are considered formal channels, such as R\&D projects, contract research, contract consultations, licensing agreements, patents, spin-offs, and U-P doctoral theses; whereas scientific publications, meetings, conferences, and training workshops were considered to be informal channels.

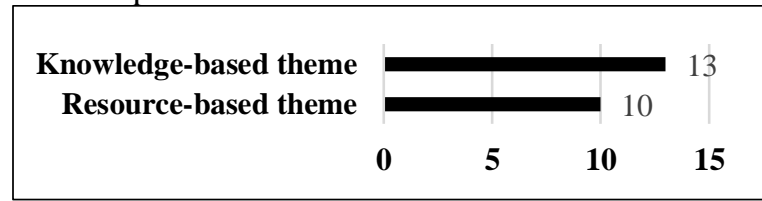

Figure 4. SC-UPP research themes

The third research question discusses research methods and participants' categories in the related studies. There were two streams of research methods in which nearly half of the studies were doing quantitative methods (44\%), while others were applying qualitative methods (39\%). The survey study design was the most commonly used among quantitative studies [15-17, 19, 34, 36, 37, 39]. Followed by one experiments design [38], one quasiexperiments research design [31]. While conducting interviews were the most popular tool among the qualitative studies [33, 35, 42, 43]. They were followed by a number of case studies [27, 32], including longitudinal case studies [40, 41]. Also, two studies applied action research design $[32,44]$, where one of them was associated with the case study design [32]. The rest of the papers (17\%) were 'review studies' [2-5]. Figure 5 shows research methods that were applied in the related studies.

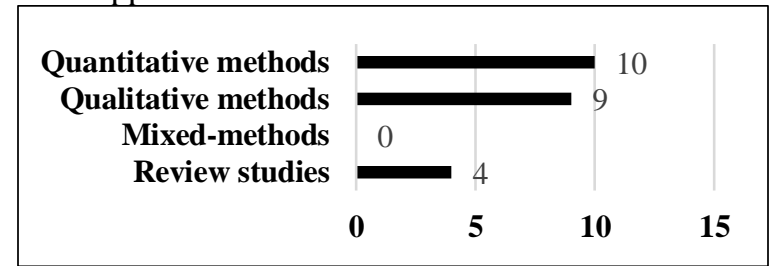

Figure 5. Types of conducted research methods

Regarding the research participants (samples) for those studies, there were three categories that include participants from only the university (U) or academic researchers, only the private sector $(\mathrm{P})$ or practitioners, or from both partners (U-P). Almost half of the papers were selecting participants from (U-P) category $(45 \%)$ $[27,32,33,35,36,38,43,44]$. Followed by the (U) category $(35 \%)[16,17,19,31,34,37,42]$. It's important to highlight that only a few studies were targeting the (P) category $(20 \%)[15,39-41]$. Figure 6 illustrates research methods that were applied in the related studies. This result corroborates with the study by de Wit-de Vries, et al. [4], that perspective of the private sector's stakeholders has not received much attention compared to the academic partners, and comprising both may contribute to moving the UPP research field forward. Additionally, it was noted that scholars preferred to conduct qualitative methods when their sample included stakeholders from the (UP) category. Papers' synthesis also revealed that SC factors in the UPP context have been examined either qualitatively or quantitatively, but results were not integrated. Therefore, there is a need for conducting mixed-methods design to bridge the gap and enrich the UPP field; by combining statistical and textual results.

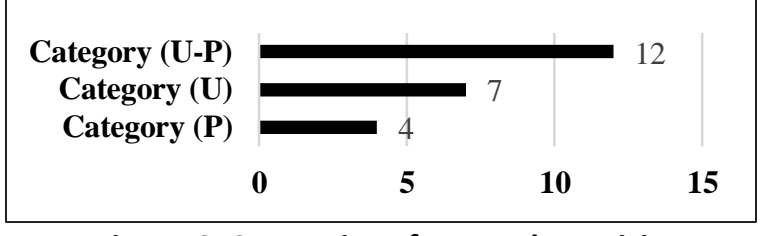

Figure 6. Categories of research participants

Given the analysis levels, the inter-organisational level was the most examined among other levels with a rate of $61 \%$. Followed by intra-organisational level of analysis in only three studies $(13 \%)$ [15, 16, 44], whereas the individual level was the least measured one in only two studies $(9 \%)[19,31]$. There was also an interest by scholars in measuring SC among mixed of different levels of analysis (17\%), such as (individual, intra-organisation, and inter-organisation) [41], or (intra-organisation, and inter-organaisation) [17, 27, 42]. Figure 7 describes SC levels of analysis that were summarised from the related studies. 
Table 3. Summary of SC factors in the papers

\begin{tabular}{|c|c|c|c|}
\hline Source & $\begin{array}{l}\text { Structural } \\
\text { dimension }\end{array}$ & $\begin{array}{l}\text { Relational } \\
\text { dimension }\end{array}$ & $\begin{array}{l}\text { Cognitive } \\
\text { dimension }\end{array}$ \\
\hline [2] & Network ties & Trust & Shared goals \\
\hline [3] & $\begin{array}{l}\text { Network (ties, } \\
\text { configuration, and } \\
\text { stability) }\end{array}$ & Trust & $\begin{array}{c}\text { Shared (goals, } \\
\text { and culture) }\end{array}$ \\
\hline [4] & - & Trust & $\begin{array}{l}\text { Shared (goals, } \\
\text { and culture) }\end{array}$ \\
\hline$[5]$ & $\begin{array}{l}\text { Networking, and } \\
\text { norm of reciprocity }\end{array}$ & Trust & $\begin{array}{l}\text { Problem } \\
\text { solving, and } \\
\text { info sharing }\end{array}$ \\
\hline [15] & $\checkmark$ & $\checkmark$ & $\checkmark$ \\
\hline$[16]$ & Network ties & Ties strength] & - \\
\hline [17] & - & Trust & - \\
\hline [19] & - & Trust & - \\
\hline [27] & $\begin{array}{l}\text { Network size, } \\
\text { centrality, structural } \\
\text { holes, and tie } \\
\text { strength }\end{array}$ & - & - \\
\hline [31] & $\begin{array}{l}\text { Networks (size, and } \\
\text { strength) }\end{array}$ & $\begin{array}{l}\text { Norms and } \\
\text { values }\end{array}$ & - \\
\hline [32] & $\checkmark$ & $\checkmark$ & $\checkmark$ \\
\hline [33] & Familiarity & $\begin{array}{c}\text { Trust, } \\
\text { commitment, } \\
\text { and integration }\end{array}$ & $\begin{array}{c}\text { Common } \\
\text { understanding }\end{array}$ \\
\hline [34] & $\begin{array}{l}\text { Assets of (network, } \\
\text { relational, and } \\
\text { participation) }\end{array}$ & Trust & - \\
\hline [35] & - & $\begin{array}{l}\text { Trust, and } \\
\text { commitment }\end{array}$ & Shared values \\
\hline [36] & $\begin{array}{c}\text { Personal } \\
\text { (participation, and } \\
\text { experience) }\end{array}$ & $\begin{array}{l}\text { Trust, and } \\
\text { promise }\end{array}$ & - \\
\hline [37] & $\begin{array}{l}\text { Assets of (network, } \\
\text { relational, and } \\
\text { participation) }\end{array}$ & Trust & - \\
\hline [38] & $\checkmark$ & $\checkmark$ & $\checkmark$ \\
\hline [39] & $\checkmark$ & $\checkmark$ & $\checkmark$ \\
\hline [40] & - & Reciprocity & $\begin{array}{l}\text { Levels of } \\
\text { general UPP } \\
\text { experience, } \\
\text { and academic } \\
\text { expertise }\end{array}$ \\
\hline [41] & - & $\begin{array}{l}\text { Trust, personal } \\
\text { contact, and } \\
\text { interaction }\end{array}$ & $\begin{array}{l}\text { Common } \\
\text { goals, and } \\
\text { mutual } \\
\text { understanding }\end{array}$ \\
\hline [42] & - & $\begin{array}{l}\text { Trust, and } \\
\text { commitment }\end{array}$ & $\begin{array}{l}\text { Shared } \\
\text { interest }\end{array}$ \\
\hline [43] & $\begin{array}{c}\text { Access to } \\
\text { (information, and } \\
\text { opportunities) }\end{array}$ & $\begin{array}{l}\text { Trust, } \\
\text { reputation, } \\
\text { status, and } \\
\text { mutual } \\
\text { obligations }\end{array}$ & $\begin{array}{c}\text { Common } \\
\text { understanding, }\end{array}$ \\
\hline [44] & Network stability & Trust & $\begin{array}{l}\text { Shared (goals, } \\
\text { and vision) }\end{array}$ \\
\hline
\end{tabular}

' $\checkmark '=$ SC dimension was measured as a one construct; '-'=SC dimension was not considered in the measurement.

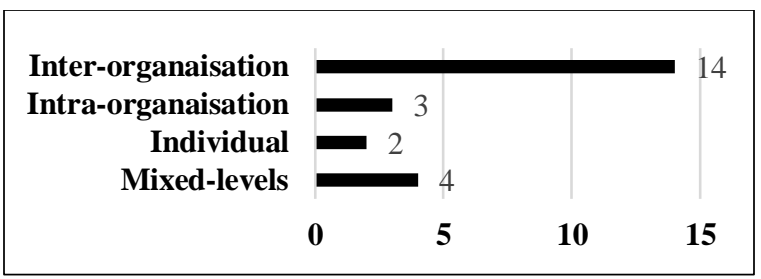

Figure 7. SC levels of analysis

The fourth research question refers to the theoretical contributions of SC that has been investigated in related UPP literature within a variety of topics. Table 3 presented a summary of SC factors studied in the selected papers and listed against each SC dimension. For SC's dimensions proposed by Nahapiet and Ghoshal [13], the relational dimension was the most examined dimension, followed by structural and then cognitive dimensions. Comparing to structural and relational in SC-UPP literature, studies on cognitive dimension are inconsistent and haven't been investigated as much as the other two dimensions; and that might be attributed to difficulties in measuring SC factors $[4,13,16]$. With respect to factors, trust (relational) was proved to be the most critical factor among others, followed by network ties (structural) and then shared goals (cognitive). In some studies [15, 32, 38, 39], SC factors were not specifically determined; thus, ' $\checkmark$ ' symbol refers to each dimension that measured in the corresponding paper. They considered SC as one construct formed by its three main dimensions without mentioning factors that being embedded, as proposed by [25]. Those studies were included since they met the inclusion criteria. Also, the "-' symbol in Table 3 refers to the non-examined dimensions, as some papers highlighted only one or two dimensions instead of analysing all three SC three dimensions.

Besides SC, there were other theoretical lenses were applied in a few studies. 'Absorptive capacity theory' was the most mentioned one associated with $\mathrm{SC}$ in related literature $[4,32,39,40]$, followed by 'relationship marketing theory' [35], and 'stimulus organism response theory' [34]. 'Absorptive capacity theory' and SC were proved to positively influence an organisation's ability to create the appropriate values. It refers to the organisation's ability "to recognise the value of new, external information, assimilate it, and apply it to commercial ends" [45].

As the final outcome (construct) that was evaluated in papers, results were summarised into four categories: knowledge-based activities, innovation, UPP aspects, and resource-based activities, as shown in Figure 8. Knowledge-based activities were also stated in the $30 \%$ of papers as 'knowledge sharing' [17], 'KT and TT' [19], 'KT success' [4], 'KT 
strategies' [3], 'KT' [27], 'knowledge creation' [35], and 'knowledge chain' [36]. Innovation was reported in the $26 \%$ of papers as 'innovation' $[2,32,39-41]$ and 'innovation performance' [15]. Innovation is associated with SC as actors' resources levels (e.g. trust) and is positively related to the performance of innovative projects. In addition, improving long-term SC will facilitate KT between partners and also foster innovation. Because KT is a complex process that gets enhanced across long-term relationships; yet, interorganisational KT is more complicated than transferring knowledge at the individual level. Resource-based activities were presented in the 17\% of papers as 'academic research performance' [16], 'graduate students outcome' [31], 'appropriate partner selection' [38] that requires an effective amount of participants' SC to complete shared projects, and 'shared activities (mechanisms)' [42] which would evolve through partners' SC. SC resources, such as trust, shared goals, and network ties, have been proven to facilitate and formulate a successful partnership between partners. In the final category, UPP aspects were reported in the $26 \%$ of papers as 'UPP formation' $[33,34,37]$, and 'UPP success' [5, 43, 44].

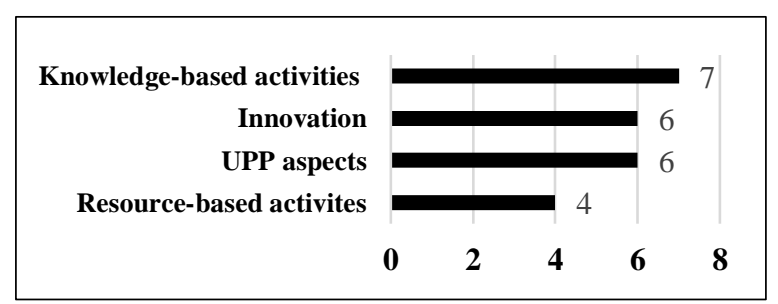

Figure 8. Categories of evaluated outcomes

It is also noted that some studies involved external construct as a mediator to play certain roles, such as 'communication' that helps to facilitate KT and to overcome KT-UPP barriers, where lack of communication hinders KT-UPP. 'Absorptive capacity' was also considered to strengthen actors' willingness to transfer knowledge [2, 4, 41]. Thus, based on the findings, a theoretical framework on how $\mathrm{SC}$ relates to evaluated outcomes in the UPP context is proposed, as presented in Figure 9.

UPP is evolving through a long term SC between partners. SC is constructed through a range of good quality resources between partners via UPP mechanisms (see Table 1), which contributes to strengthening the partners' relationships, raising the trust, and compromising cognitive differences in partnerships' goals, which then lead to boosting UPP outcomes. SC is investigated in different ways based on the nature of the study, where SC's three dimensions were not necessary to be all involved, and SC's factors were also selected to meet research objectives. The following framework is proposed for the relevant stakeholders in the universities and the private sector to guide them on how to foster successful partnerships and promote mutual benefits.

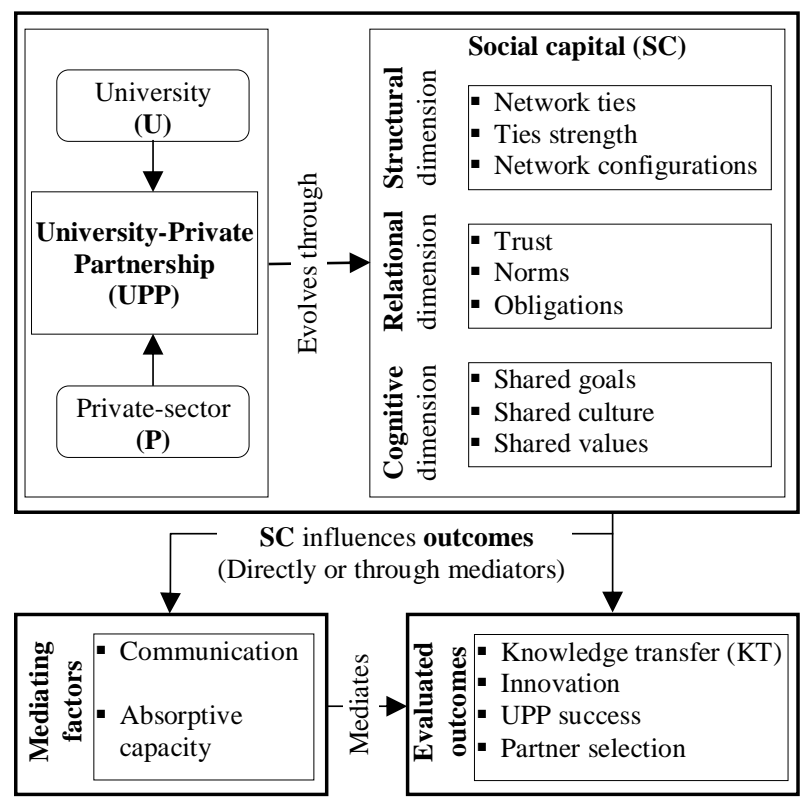

Figure 9. The proposed theoretical framework

\section{Conclusion and future directions}

In this paper, a systematic review is reported based on the last two decades of scholarly work in which 23 peer-reviewed papers were analysed and synthesised. This review focuses on the direct UPP and how SC influences that relationship. In particular, it focuses on how SC contributes to preparing the ground for researchers, in the context of SC and direct UPP, by raising this main research question, "How would the theoretical lens of SC inform research and learnings about UPP?". During the review process, it was noticeable that 'university-industry collaboration' was the mhost commonly used term among others to describe partnerships between universities and the private sector. Terminology to describe other models of UPP remained inconsistent. The findings from this review have yielded further research directions for expanding research boundaries to empirically or theoretically cover more aspects of the SC-UPP context and enrich future findings as follows:

- Other partnership models; future research would explore other emerging models, e.g. 'triple-helix', through the SC theory lens to compare findings with the traditional direct UPP and measure how SC level differs among all actors/ partners. 
- Intermediation mechanisms; intermediaries entities such as universities' technology transfer offices 'TTOs', have been proven to facilitate UPP. Future research would investigate how SC theory would influence the relationships between intermediaries and UPP's actors in different UPP models, and how such different types of intermediaries would help to mitigate partnerships' barriers, particularly cognitive differences issues.

- SC cognitive dimension; this dimension of SC has not been examined much in the KT-UPP context compared to other dimensions, which might be attributed to the difficulties in measuring SC cognitive factors.

- Theoretical perspective; more studies could also be done on the SC associated with other related theories in the UPP field, such as 'Absorptive capacity theory', as that would enrich the findings.

- Methodological perspective; the mixed-methods research design is rare within the UPP field of study, in which integrating quantitative and qualitative methods would help to move the field forward.

\section{References}

[1] H. Etzkowitz and L. Leydesdorff, "The dynamics of innovation: From National Systems and "mode 2" to a Triple Helix of university-industry-government relations," Research Policy, Article vol. 29, no. 2, pp. 109-123, 2000, doi: 10.1016/S0048-7333(99)00055-4.

[2] A. Thomas and J. Paul, "Knowledge transfer and innovation through university-industry partnership: an integrated theoretical view," Knowledge Management Research \& Practice, vol. 17, no. 4, pp. 436-448, 2019, doi: 10.1080/14778238.2018.1552485.

[3] J. Robertson, I. P. McCarthy, and L. Pitt, "Leveraging social capital in university-industry knowledge transfer strategies: a comparative positioning framework," Knowledge Management Research \& Practice, vol. 17, no. 4, pp. 461-472, 2019, doi: 10.1080/14778238.2019.1589396.

[4] E. de Wit-de Vries, W. A. Dolfsma, H. J. van der Windt, and M. P. Gerkema, "Knowledge transfer in universityindustry research partnerships: a review," The Journal of Technology Transfer, vol. 44, no. 4, pp. 1236-1255, 2019, doi: 10.1007/s10961-018-9660-x.

[5] A. Chakrabarti and M. Santoro, "Building social capital and learning environment in university-industry relationships," Int. J. Learning and Intellectual Capital, vol. 1, pp. 19-36, 2004, doi: 10.1504/IJLIC.2004.004421.

[6] M. Perkmann et al., "Academic engagement and commercialisation: A review of the literature on university-industry relations," Research Policy, vol. 42, no. 2, pp. 423-442, 2013, doi: https://doi.org/10.1016/j.respol.2012.09.007.

[7] J. Molas-Gallart, A. Salter, P. Patel, A. Scott, and X. Duran, "Measuring third stream activities," Final report to the Russell Group of Universities. Brighton: SPRU, University of Sussex, 2002.

[8] OECD, Private Sector Engagement for Sustainable Development. 2016.

[9] D. Cooper, "University-Civil Society (U-CS) research relationships: The importance of a 'fourth helix' alongside the 'triple helix' of University-IndustryGovernment (U-I-G) relations," South African Review of Sociology, vol. 40, no. 2, pp. 153-180, 2009, doi: 10.1080/21528586.2009.10425106.

[10] M. Perkmann and K. Walsh, "University-industry relationships and open innovation: Towards a research agenda," International Journal of Management Reviews, vol. 9, no. 4, pp. 259-280, 2007, doi: 10.1111/j.1468-2370.2007.00225.x.

[11] J. Jacobs, The death and life of great American cities. New York: Random House, 1961.

[12] J. Häuberer, Social Capital Theory Towards a Methodological Foundation, 1st ed. ed. Wiesbaden: VS Verlag für Sozialwissenschaften, 2011.

[13] J. Nahapiet and S. Ghoshal, "Social Capital, Intellectual Capital, and the Organizational Advantage," The Academy of Management Review, vol. 23, no. 2, pp. 242-266, 1998, doi: 10.2307/259373.

[14] M. Woolcock, "Social capital and economic development: Toward a theoretical synthesis and policy framework," Theory and Society, vol. 27, no. 2, pp. 151-208, 1998, doi: 10.1023/A:1006884930135.

[15] A.-F. Abdulai, L. Murphy, and B. Thomas, "UNIVERSITY KNOWLEDGE TRANSFER AND INNOVATION PERFORMANCE IN FIRMS: THE GHANAIAN EXPERIENCE," International Journal of Innovation Management, vol. 24, no. 03, p. 2050023 , 2020, doi: 10.1142/s1363919620500231.

[16] B. Zhang and X. Wang, "Empirical study on influence of university-industry collaboration on research performance and moderating effect of social capital: evidence from engineering academics in China," Scientometrics, vol. 113, no. 1, pp. 257-277, 2017, doi: 10.1007/s11192-017-2464-1.

[17] A. Gerbin and M. Drnovsek, "Knowledge-sharing restrictions in the life sciences: personal and contextspecific factors in academia-industry knowledge transfer," (in English), Journal of Knowledge Management, vol. 24, no. 7, pp. 1533-1557, 2020, doi: http://dx.doi.org/10.1108/JKM-11-2019-0651.

[18] A. C. Inkpen and E. W. K. Tsang, "Social capital networks, and knowledge transfer," Academy of Management Review, vol. 30, no. 1, pp. 146-165, 2005, doi: 10.5465/AMR.2005.15281445.

[19] B. Kalar and B. Antoncic, "Social capital of academics and their engagement in technology and knowledge transfer," Science \& Public Policy (SPP), Article vol. 43, no. 5, pp. 646-659, 2016, doi: 10.1093/scipol/scv062.

[20] J. S. Coleman, "Social Capital in the Creation of Human Capital," American Journal of Sociology, vol. 94, pp. S95-S120, 1988.

[21] P. Bourdieu and L. J. D. Wacquant, An invitation to reflexive sociology. Chicago: University of Chicago Press, 1992. 
[22] R. D. Putnam, "BOWLING ALONE: AMERICA'S DECLINING SOCIAL CAPITAL," Journal of Democracy, Article vol. 6, no. 1, pp. 65-78, 1995, doi: 10.1353/jod.1995.0002.

[23] A. Portes, "Social capital: Its origins and applications in modern sociology," (in English), Annual Review of Sociology, vol. 24, p. 25, 1998.

[24] M. S. Granovetter, "The Strength of Weak Ties," American Journal of Sociology, vol. 78, no. 6, pp. 13601380, 1973.

[25] P. S. Adler and S.-W. Kwon, "SOCIAL CAPITAL: PROSPECTS FOR A NEW CONCEPT," Academy of Management Review, Article vol. 27, no. 1, pp. 17-40, 2002, doi: 10.5465/AMR.2002.5922314.

[26] M. Woolcock and D. Narayan, "Social Capital: Implications for Development Theory, Research, and Policy," The World Bank Research Observer, vol. 15, no. 2, pp. 225-249, 2000.

[27] R. Filieri, R. C. McNally, M. O'Dwyer, and L. O'Malley, "Structural social capital evolution and knowledge transfer: Evidence from an Irish pharmaceutical network," Industrial Marketing Management, vol. 43, no. 3, pp. 429-440, 2014, doi: 10.1016/j.indmarman.2013.12.011.

[28] D. Tranfield, D. Denyer, and P. Smart, "Towards a Methodology for Developing Evidence-Informed Management Knowledge by Means of Systematic Review," British Journal of Management, vol. 14, no. 3, pp. 207-222, 2003, doi: 10.1111/1467-8551.00375.

[29] S. Ankrah and O. Al-Tabbaa, "Universities-industry collaboration: A systematic review," Scandinavian Journal of Management, vol. 31, no. 3, pp. 387-408, 2015 ,

doi: https://doi.org/10.1016/j.scaman.2015.02.003.

[30] O. Al-Tabbaa and S. Ankrah, "'Engineered' UniversityIndustry Collaboration: A Social Capital Perspective," European Management Review, vol. 16, no. 3, pp. 543565, 2019, doi: 10.1111/emre.12174.

[31] O. Leonchuk and D. O. Gray, "Scientific and technological (human) social capital formation and Industry-University Cooperative Research Centers: a quasi-experimental evaluation of graduate student outcomes," The Journal of Technology Transfer, vol. 44, no. 5, pp. 1638-1664, 2019, doi: 10.1007/s 10961017-9613-9.

[32] M. Mäkimattila, T. Junell, and T. Rantala, "Developing collaboration structures for university-industry interaction and innovations," European Journal of Innovation Management, vol. 18, no. 4, pp. 451-470, 2015, doi: 10.1108/EJIM-05-2013-0044.

[33] S. Philbin, "Process model for university-industry research collaboration," European Journal of Innovation Management, Article 2008, doi: 10.1108/14601060810911138.

[34] S. H. Ting, S. Yahya, and C. L. Tan, "The influence of researcher competence on university-industry collaboration: The mediating role of domain knowledge transfers and spillovers," Journal of Entrepreneurship in Emerging Economies, vol. 11, no. 2, pp. 277-303, 2019a, doi: 10.1108/jeee-06-2018-0054.
[35] A. Tootell, E. Kyriazis, J. Billsberry, V. Ambrosini, S. Garrett-Jones, and G. Wallace, "Knowledge creation in complex inter-organizational arrangements: understanding the barriers and enablers of universityindustry knowledge creation in science-based cooperation," Journal of Knowledge Management, Article 2020, doi: 10.1108/JKM-06-2020-0461.

[36] H. Yang, "Empirical Analysis on the Universityindustry Knowledge Chain Conflict Reasons," (in English), Revista Ibérica de Sistemas e Tecnologias de Informação, no. E8, pp. 39-48, 2016.

[37] S. H. Ting, S. Yahya, and C. L. Tan, "ImportancePerformance Matrix Analysis of the Researcher's Competence in the Formation of University-Industry Collaboration Using Smart PLS," Public Organization Review, 2019b, doi: 10.1007/s11115-018-00435-z.

[38] C. Wei, Q. Hui, and Y. Yu-ning, "A Partner Selection Strategy of Industry-University Collaboration Based on Social Capital and Network Risk," in 2017 International Conference on Management Science and Engineering (ICMSE), 2017, pp. 3-8, doi: 10.1109/ICMSE.2017.8574415.

[39] R. Martínez-Cañas and P. Ruiz-Palomino, "Social Capital Generation Inside Science Parks: An Analysis Of Business-University Relationships," (in English), International Journal of Management and Information Systems, vol. 14, no. 4, pp. 45-50, 2010.

[40] M. Steinmo and E. Rasmussen, "The interplay of cognitive and relational social capital dimensions in university-industry collaboration: Overcoming the experience barrier," Research Policy, vol. 47, no. 10, pp. 1964-1974, 2018, doi: 10.1016/j.respol.2018.07.004.

[41] M. Steinmo, "Collaboration for Innovation: A Case Study on How Social Capital Mitigates Collaborative Challenges in University-Industry Research Alliances," Industry and Innovation, vol. 22, no. 7, pp. 597-624, 2015, doi: 10.1080/13662716.2015.1105127.

[42] M. L. Pinheiro, J. C. Pinho, and C. Lucas, "The outset of U-I R \& D relationships: the specific case of biological sciences," (in English), European Journal of Innovation Management, vol. 18, no. 3, pp. 282-306, 2015.

[43] T. Thune, "University-industry collaboration: The network embeddedness approach," Science and Public Policy, Article 2007, doi: 10.3152/030234207X206902.

[44] K. Dalkir, M. Iancu, and D. Oliveira, "The Effects of Inter-Organizational Communication on Collaborative Intellectual Capital," in European Conference on Intangibles and Intellectual Capital, ed. Kidmore End: Academic Conferences International Limited, 2019, pp. 89-96,XI.

[45] W. M. Cohen and D. A. Levinthal, "Absorptive Capacity: A New Perspective on Learning and Innovation," Administrative Science Quarterly, vol. 35, no. 1, pp. 128-152, 1990, doi: 10.2307/2393553. 